NBER WORKING PAPER SERIES

DISAGGREGATING THE EFFECT OF

THE BUSINESS CYCLE ON

THE DISTRIBUTION OF INCOME

Rebecca M. Blank

Working Paper No. 2397

NATIONAL BUREAU OF ECONOMIC RESEARCH

1050 Massachusetts Avenue

Cambridge, MA 02138

October 1987

This project was funded by the Small Grants Program of the Institute for Research on Poverty. Helpful comments were made by Charles Beach, Alan Blinder, David Card, Peter Gottschalk. Michael White, members of the Princeton Industrial Relations Seminar, and attendees at the Small Grants Workshop, Institute for Research on Poverty, May 1985. The research reported here is part of the NBER's research program in Labor Studies. Any opinions expressed are those of the author and not those of the National Bureau of Economic Research. 
NBER Working Paper \#2397

October 1987

\title{
Disaggregating the Effect of the Business \\ Cycle on the Distribution of Income
}

\section{ABSTRACT}

\begin{abstract}
This paper disaggregates total household income into a complete set of components and studies the comparative cyclicality of these components to economic growth. Comparisons of the relative responsiveness to GNP growth of wages, hours of work, and total labor market income of heads and wives, and transfer income sources of households are made across income, race, sex and age groups. This provides a picture of the channels by which economic growth produces income change. Significant differences in elasticities are found to exist both between different income components and between different population groups for the same components. The narrowing income distribution in times of high growth occurs primarily because of large elasticities on head's labor market income among the poor. Both wages and hours show evidence of cyclicality. The labor market earnings of women -- both wives and household heads -- are far less responsive to growth. Cyclicality in transfer income varies enormously between population groups and by type of transfer.
\end{abstract}

Rebecca M. Blank Woodrow Wilson School

Princeton University

Princeton, NJ 08544 


\section{INTRODUCTION}

A great deal of political discussion in recent years has focussed on the extent to which economic growth helps relatively disadvantaged groups in the United States. While some claim that the best thing we can do for the poor is to make the economy grow, others contend that economic growth passes by many low income groups and simply leaves them worse off, relative to the rest of the society.

Previous research concerning the effect of the macroeconomy on the income distribution has shown that both claims have some validity. In aggregate data, economic growth appears to have some narrowing effect on the income distribution. ${ }^{3}$ But there are specific demographic groups that seem less responsive (elderly and female-headed households) or more responsive (young and black male-headed households) to economic growth. However, since these studies are based on aggregate income variables, they make little attempt to investigate which components of income respond most strongly to the economy and which are least affected. ${ }^{2}$ Using micro data, one branch of reseach has explored the cyclicality of specific income components, such as male wage rates or wives' labor force participation. ${ }^{3}$ While these studies provide a detailed analysis of a particular economic variable, they are rarely interested in comparing cyclical effects between income groups, or in looking at how the cyclicality of a particular component affects the cyclicality of aggregate income. More recently, a few studies have utilized micro data to ask broader income distribution questions. "This research has investigated how changes in the macroeconomy induce changes in employment and income among a variety of demographic groups. 
This paper extends the approach taken in these latter studies, using a national population sample which provides information on total household income and all of its components. The data is analyzed by income groups and by race, sex and age groupings, allowing me to study the comparative cyclicality of the income components of each group to economic growth. The research is designed to provide a more comprehensive picture of the channels by which economic growth produces income change, providing comparative information on the relative responsiveness of major income components both within and across demographic groups. In contrast to earlier research, this study investigates a broader set of demographic groupings, looks at a more disaggregate set of income components, and estimates the cyclical effects of the macroeconomy in a way which imposes no pre-determined structural model on the data. ${ }^{5}$ The results presented here are interesting not just because they provide additional empirical evidence on the effect of the business cycle on income distribution, but also because they allow comparative statements to be made about the magnitude of cyclical effects across a range of variables and populations.

This research indicates that aggregate income statistics hide very significant differences in earning and income patterns between different population groups. The major results are as follows:

(1) This study confirms that the income distribution narrows in times of economic growth. This occurs despite the fact that low income groups have a very low share of labor market income compared to high income quartiles. The narrowing occurs because the cyclicality of household head's labor market income among low income groups is very 
strong and overcomes the differential in shares. In fact, the procyclicality in head's' labor market incomes is consistently stronger than procyclicality in total income for almost all groups. Both wages and hours show procyclical effects for household heads (a result that is at least partially dependent upon the inclusive definition of labor income which is used to calculate average hourly earnings.)

(2) Women's earnings are remarkably non-responsive to macroeconomic changes. Among wives, wages are procyclical, but their hours show little change with the cycle, except among a few groups. Female household heads show less cyclicality than any other group across a range of their income components. Black women in particular show only small responses to economic growth. A major conclusion of this study is that women's labor market earnings in general move far less with the general economy than do men's. Their initial elasticity response is lower and it falls off rapidly as economic growth continues.

(3) Transfer income -- public and private -- is counter-cyclical for most middle income groups. Lower income groups show little change in their transfers over the cycle. However cyclicality varies greatly by the type of transfer. Unemployment and worker's compensation and AFDC are very counter-cyclical.

(4) Not only do income differences between groups narrow when the economy grows, but income dispersion (as measured by the coefficient of ve-iation) also narrows within almost all groups, primarily because the dispersion of annual hours among household heads narrows. This implies that the worst off among these groups catch up relative to the rest of the population by taking advantage of greater employment opportunities. 
Female and elderly heads and wives show less evidence of this withingroup income narrowing than do other population groups.

\section{DEFINING THE PROBLEM}

Before describing the data or the methodology of this study in more detail, this section defines the components of income and the population groups which this research investigates.

For any household in any given year, total household income can be expressed as

$$
\text { Inc }=\mathrm{LIncH}+\mathrm{LIncW}+\text { Transfers }+ \text { OthInc, }
$$

where LIncH represents the labor income of the household head and can be written as

$$
\mathrm{LIncH}=\mathrm{AHE} \because \text { Hours, }
$$

where AHE represents average hourly earnings and Hours represents annual hours of work. 6

Similarly, LIncW in equation 1 represents labor income of the wife and can be written as

$$
\text { LIncW = AHEW:HoursW, }
$$

where AHEW and HoursW represent average hourly earnings and annual hours of work of the wife.

Transfers in equation 1 represents total transfer income from all sources. It can be further decomposed into

$$
\begin{gathered}
\text { Transfers = AFDC + ChSup\&A + SocSec + OthRetInc + } \\
\text { U\&WComp + OthTrans, }
\end{gathered}
$$

where AFDC represents income from Aid to Families with Dependent Children, the primary welfare program available to low income households with children. ChSup\&A represents child support or alimony from private 
sources, while SocSec represents income from the Social Security program. OthRetInc stands for other retirement income, including all pension funds or annuities exclusive of those received from Social Security. U\&WComp represents income from Unemployment or Worker's Compensation programs. OthTrans is all other transfer income, and includes cash income from other welfare programs, ${ }^{7}$ help from relatives, or other sources of transfer income.

OthInc in equation 1 is the residual category for total income and includes all income not contained elsewhere. This is asset income, rents, dividends, and interest payments. The category also contains the labor market earnings of any household member other than the head or the wife. ${ }^{8}$ Equations (1) through (4) present the components of income and of income change on which the rest of this paper will focus.

The above equations are written for an individual. But as noted earlier, our interest is in the behavior of particular groups of individuals in the population. The twelve household groups which will be investigated can be divided into three major categories:

Hous ehold Income Groups

$$
\text { Poor }
$$

Bottom Quartile

Second Quartile

Third Quartile

Top Quartile

"Poor" is defined as all households whose total income is less than $125 \%$ of a given "Income/Need Standard." This standard is very close to (although not completely identical with) the official Census definition of the poverty 1 ine. ${ }^{9}$ Note also that "Poor Households" need not be a subset of "Bottom Quartile Households." Some large families may have

$\begin{array}{lc}\begin{array}{c}\text { Hous ehold } \\ \text { Race/Sex Groups }\end{array} & \text { Household } \\ \text { Black Female Heads } & \text { Elderly Groups } \\ \text { White Female Heads } & \text { Young }(\text { Age }>65) \text { Heads } \\ \text { Black Male Heads } & \text { Middle }(65 \geq \text { Age } \geq 24) \\ \text { White Male Heads } & \text { Heads }\end{array}$

Heads 
income levels that place them within the second quartile, but have need levels large enough to piace them in the Poor category as well.

Focussing on the components of income defined above for each of

the 12 population groups, I am interested in three primary questions:

(1) On average, how do these income components differ between these populations? What is the mean level of each component or the mean share of each component in total income?

(2) How do these components change as the economy grows? What is the comparative elasticity of each income component to GNP growth within each population?

(3) Are there changes in the variances of these income components as GNP changes? Many people claim that income variances within groups are likely to widen as the economy grows. This "bifurcation" hypothesis claims that only some members of a group are able to take advantage of economic growth. In particular, this story has frequently been told for black men. In contrast, others claim that economic growth allows those who are behind to "catch up." The unemployed get jobs, and the underemployed work more hours. This might imply that variances among some groups will decrease during economic growth, as the "worse off" have an opportunity to earn more income. The variance tests will allow me to distinguish between these hypotheses.

\section{DATA}

The data used in this study are from the Panel Study of Income Dynamics (PSID), collected by the Survey Research Center at the University of Michigan. I use the survey years 1970 to 1982 , which provide data on annual household income from 1969 to $1981 .{ }^{10}$ Using the 
household tape, I extract all the variables necessary to calculate the income components described in equations (1) through (4) (along with a variety of demographic variables) for every household over the entire 13 years. Working with a data set of this size always raises numerous empirical issues. Information on how problems of data inconsistency, household splitoffs, and weighting were handled is available from the author upon request.

The advantage of the PSID is that it provides a continuous history on income changes within the same household, allowing one to calculate how changes in aggregate economic growth translate into changes in household income. However, while there are clear advantages to observing the same household over time, there is a major problem in trying to follow households for several years. Only a small percentage of households fall into the same income or demographic category for an extended period. In particular, female-headed households are formed and dissolve frequently; low income households move in and out of poverty status; young household heads grow older; and so on. This paper is not concerned with the long-term dynamics of income change for given households. My concern is with the effect of changes in economic growth on income components of households within each of these categories in any year. As a result, rather than following the same households over the entire time period, I select 12 "adjacent year" samples, each sample crntaining all those households whose head remains the same for a twoyear period. These range from a $1969 / 1970$ sample to a $1980 / 1981$ sample. Obviously, the $1969 / 1970$ sample looks a great deal like the $1970 / 1971$ sample, and includes many of the same households. But it is not exactly 
identical, as some changes in head do occur over these years. (The weighted samples look virtually identical, as they should.)

Thus I have 12 samples, each containing data on two consecutive years for the same households. I can separate each of these samples into the 12 population groups defined above, where the household is classified according to its total income in the first year of each twoyear period, or by the race, sex or age of its head. Then, for any twoyear period, for any population, I can calculate the means and variances on all income variables for both years and the mean differences between years. Putting together the data from all twelve samples provides a 12-year time series on mean changes in each income component among all members of each population group. Thus, for every two-year period, for every income component, and for every population group, I can derive estimates of means, mean changes, shares, variances, and other variables of interest. ${ }^{1}$ These variables can then be related to changes in the general economic growth rate. ${ }^{22}$

\section{OBSERVING THE DATA}

Before estimating the effect of business cycles, this section will investigate the income patterns that exist between the 12 income, age, and race/sex population groups. Equations (1) through (4) define a set of income components that compose total income for any given household. To calculate means of these income components for an entire population it is necessary to distinguish between the mean level of an income component available among those who receive it, and the mean number of recipients of that component. Table 1 shows the components of total income averaged over the entire 12 year period for all 12 population 
groups in which I am interested. Shown are the mean (over the 12 years) and the income share of each variable for each population group. ${ }^{13}$ The mean of each component is calculated only for those households who report receiving positive income from that source. The percent in each population group that receives income from each source is also shown.

Part A of Table 1 shows the mean of total income for each group and the share breakdown into its four main components. Part B shows the components of labor income calculated among those households which receive labor income from the head. Part $\mathrm{C}$ shows the components of wife's labor income calculated from among those households with a working wife. Part $D$ shows mean transfer income among those who receive it, and the share of each of its components among recipients. Some interesting patterns emerge.

First, looking at Part $A$, it is clear that labor income share increases dramatically as income rises, from $41.1 \%$ in the bottom quartile to $80.4 \%$ in the top quartile. This is due to an increase in the level of both head's and wife's labor income across income quartiles and an increase in the probability that the head and wife will work. Low labor income shares among low income households are hardly surprising. Among the poor, $54 \%$ of the households are female-headed (a group with traditionally lower earnings and labor market participation), while $57 \%$ report themselves as having some health problem that interferes with work. Among the top quartile, only $4 \%$ of the households are female-headed, and only $15 \%$ report such health problems. The increase in the share of wife's labor income across income levels is due to the increase in level of income earned by wives who work, an increase 


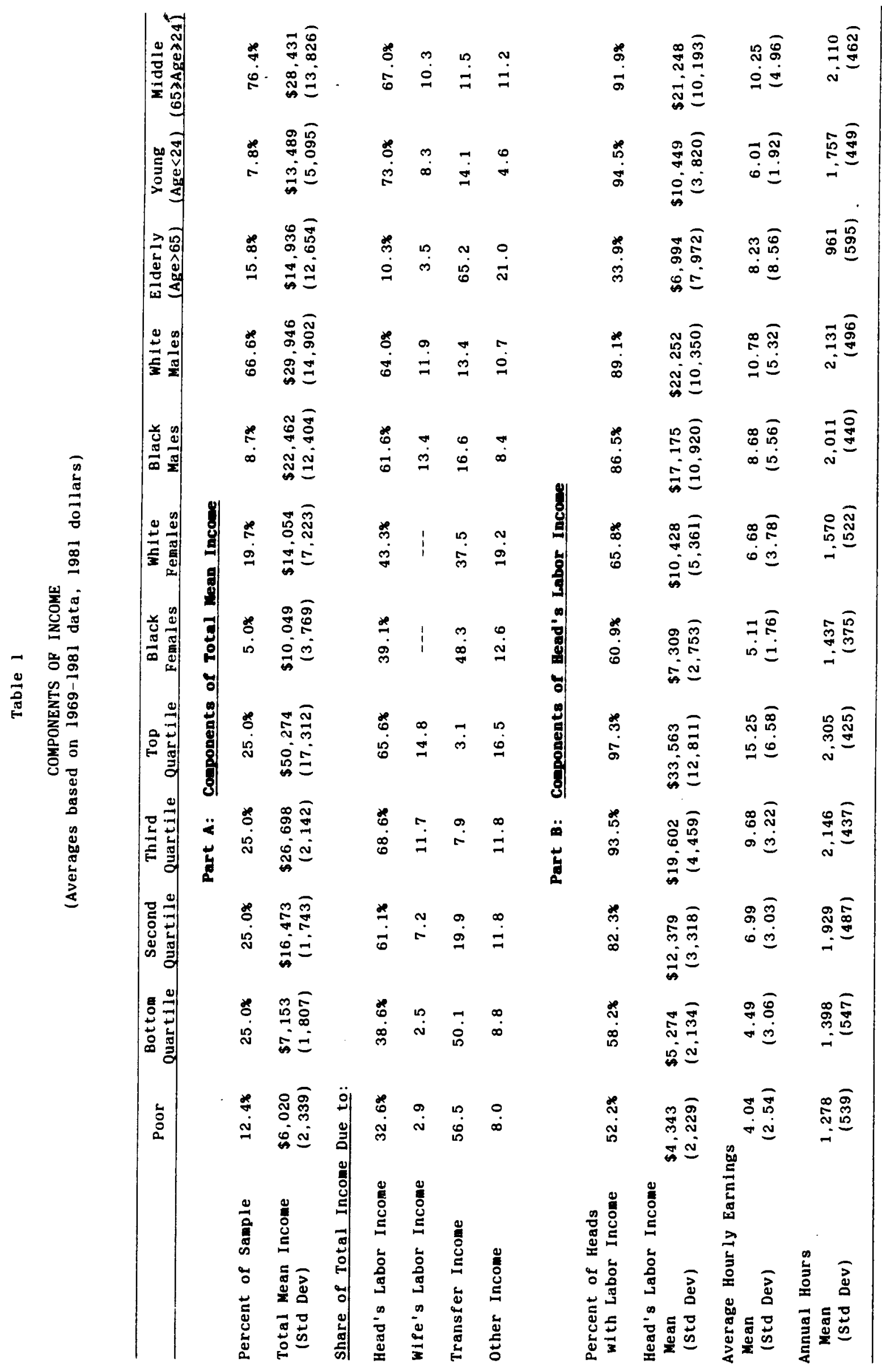




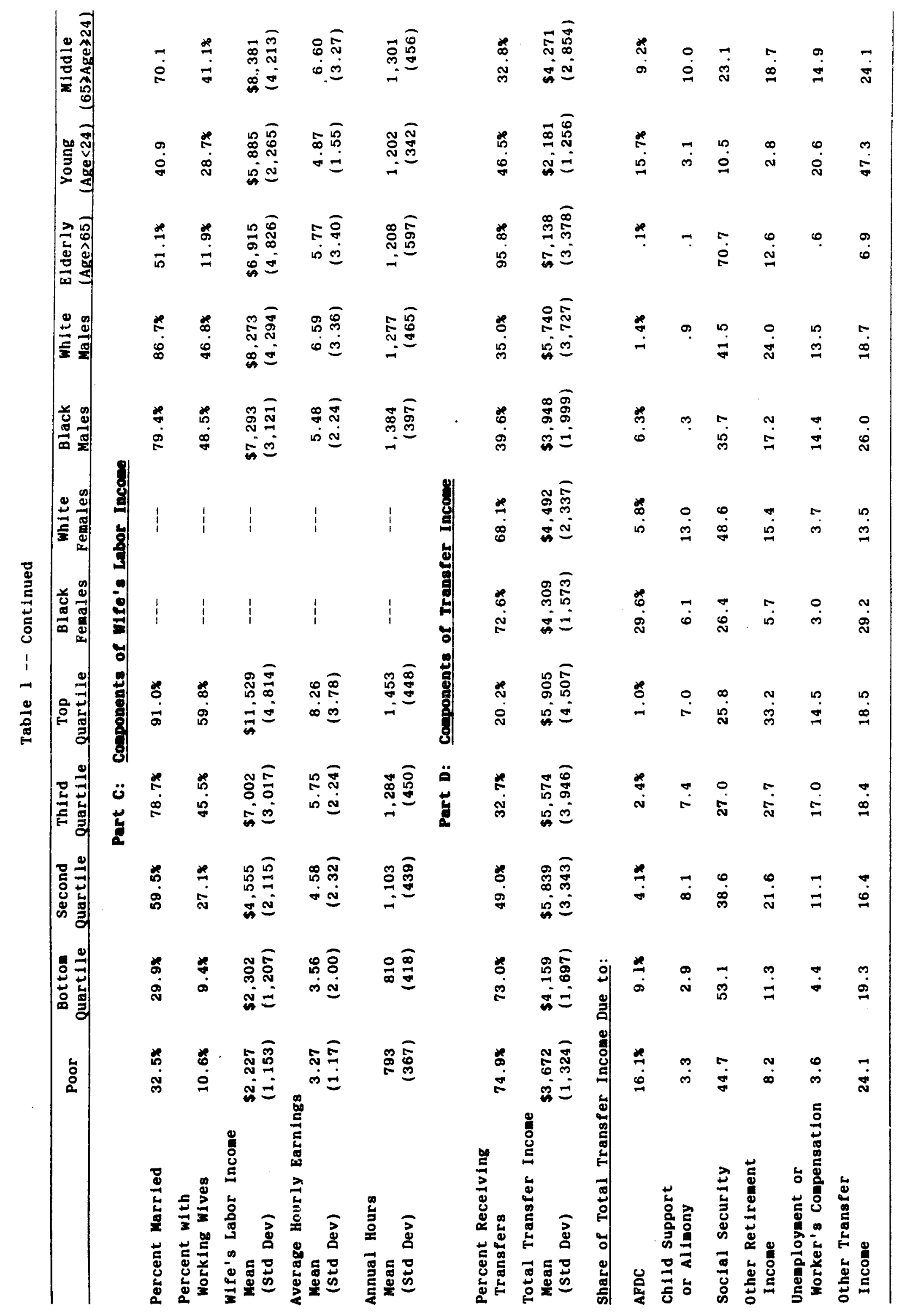


in the percent of wives who work, and an increase in the percent of heads who are married. (See the top of Part C.) Share of total income from transfers decreases dramatically over the income scale, while the share of "other income" increases.

Figure 1 shows how the mean incomes of these groups relate to each other. Mean income for the entire population is $\$ 25,128$. The quartile breaks occur at $\$ 11,763, \$ 21,332$, and $\$ 32,859$. While many people are grouped near the mean, there is clearly a large and extended upper tail. Like low income families in general, black and white female-headed households receive a relatively low percentage of their income from the labor market, as do the elderly. In contrast, black males and the young rely heavily on the labor market. We would expect, a priori, that growth in the economy would initially help those groups who are closely tied to the labor market more than it helps others. As noted above, previous research has indicated that female and elderly-headed households are less responsive to economic changes.

Among the poor, the very low amount of labor market income received might indicate that this group also is less affected by economic growth. The "trickling down" hypothesis does not look promising when less than $36 \%$ of the income of the poor is directly tied to the labor market. In order for the poor to gain relative to other groups, the elasticity of labor income and labor market participation with respect to GNP must be very strong for low income workers.

Part B shows the mean levels and standard deviations for the components of head's labor income. This table indicates first that wage differentials among groups are greater than hours differentials. For 
instance, average hourly earnings among the top quartile are 3.4 times greater than average hourly earnings among the bottom quartile. The comparative figure for hours in these groups is $1.6 .{ }^{14}$ This is also true between race and sex groups, where wage levels vary more than hours. Part C shows mean levels and standard deviations for the components of wife's labor income. Here are basically the same patterns as were observed within head's labor income, but with smaller differences between the groups. The relative wages of the wives in wealthier households are higher than the wages of wives of the bottom quartile, but the difference is less than is found among head's wages. This at least partially reflects the fact that marital sorting along economic lines is not perfect and the highest-earning husbands are not always married to the highest-earning wives.

Wives of black males earn higher wages than black female heads, but they work fewer hours. Wives of white heads earn about the same wage as white female heads, but also work less. The elderly are the only group for whom labor income of the wife is about equal to the labor income of the head. But elderly wives earn a lower wage than their husbands, making up the difference by working more hours.

Finally, Part D shows mean transfer levels between the groups and the relative shares due to each of the six components of transfer income. The patterns are consistent with the nature of these income sources. AFDC is most important for low-income and female-headed households. Child support is most important for middle-income households and women. Social Security is particularly important for the elderly and low income. Other retirement income is most important among 
higher-income households. Unemployment and worker's compensation is most important to the middle income and young households.

I was rather surprised by the percent of households receiving some form of transfer income. Among the poor, close to one quarter receive no transfers--a number that I find surprisingly high. ${ }^{15}$ Among the top quartile, one fifth of households still receive transfer income, largely in the form of non-welfare transfers such as other retirement income.

Table 1 shows the mean patterns among income components for these groups. However, the focus of this paper is on changes in income. The business cycle effects are those income changes related to the macroeconomy that occur in addition to the secular income changes which these populations typically experience. For the population as a whole over these 12 years, real median income was effectively stagnant, so there was no overall income trend. ${ }^{16}$ (However, there are secular income changes occuring within particular groups, relating to life cycle changes as well as regression toward the mean. For data on these effects, see the working paper version of this research, Blank (1985).)

\section{THE RESPONSIVENESS OF INCOME COMPONENTS TO THE CYCLE}

This research requires that a general macroeconomic variable (GNP growth) be related to specific microeconomic concepts, such as wage rates or hours of work. The most obvious response -- to enter GNP growth into micro-data regressions estimating wages or hours -- is typically ineffective. The range of variation in individual responses is almost always so great that aggregate variables rarely appear to be significant. ${ }^{17}$ 
This paper takes a different approach. The methodology outlined below provides one way of combining a great deal of data on individual households into more aggregate variables which are more readily compared with GNP growth rates. Since my primary interest is in the comparative responsiveness of different income sources to economic growth among the 12 populations, I will aggregate changes in income components within individual households in each population group and regress these mean changes for each population group against percent change in GNP across the 12 time periods. ${ }^{18}$

I choose to use two measures of the relative responsiveness of each income component to GNP. The first is the percent change in a given component induced by a $1 \%$ change in GNP. The second is the absolute or level change in a given component induced by a $1 \%$ change in GNP. These two measures provide complementary information on the effects of the economic cycle.

The percent change in the level of income component $\mathrm{X}$ is calculated over the entire population for each two year period. It explicitly includes both the recipients of $x$, as well as the nonrecipients in its calculation, thus allowing changes to occur both in the number of recipients and in the level of $X$ among recipients. Define this total percent change for year $t$ and population $j$ as ${ }^{19}$

$$
\operatorname{PctCh}(X)_{j t}=\sum_{i=1}^{n_{x_{j} t}}\left(x_{i j t+1}-x_{i j t}\right) / \sum_{i}^{n_{x_{j} t}} x_{i j t} .
$$

If I regress the percent change in variable $X$ from each of the 12 two-year samples against a constant and the percent change in GNP over these same years, the coefficient on GNP will provide an elasticity estimate. This is the regression

$$
\operatorname{PctCh}(X)_{j t}=\alpha_{1}+\alpha_{2} \operatorname{PctGNP}_{t}+e_{j t}
$$


where $\quad \operatorname{PctGNP}_{t}=\left(\mathrm{GNP}_{t+1}-\mathrm{GNP}_{t}\right) / \mathrm{GNP}_{t}$ and $e$ is a random error term. The coefficient $\alpha_{2}$ will indicate how responsive income component $\mathrm{X}$ is to macroeconomic growth and can be interpreted as the percent change in $\mathrm{X}$ due to a $1 \%$ increase in GNP. ${ }^{20}$ However, this percent elasticity has certain limitations. While it is useful in comparing the responsiveness of different income components both between and within population groups, it can appear misleading. When percent changes are calculated off numbers with large base levels, even small percent changes can imply large absolute changes, and vice versa. Since the different income components vary widely in their level values, I present not only the percent change but also the level change associated with changes in GNP.

The level change for income component $X$ for population $j$ in year $t$ is the numerator of the percent change calculation in equation (5):

$$
\operatorname{LevCh}(X)_{j t}=\sum_{i=1}^{n_{x i t}}\left(x_{i j t+1}-x_{i j t}\right) / n_{j t}
$$

This measure can also be regressed against the percent change in GNP,

$$
\operatorname{LevCh}(X)_{j t}=\beta_{1}+\beta_{2} \text { PctGNP }_{t}+u_{j t},
$$

where PctGNP is defined above and $u$ is a random error term. The coefficient $\beta_{2}$ will measure the mean dollar change in income component $X$ (among all households in population j) resulting from a $1 \%$ change in GNP .

Table 2 presents estimates of $\alpha_{2}$ and $\beta_{2}$. (Constants are included in all regressions, but not reported here.) Panels A-1 through D-1 indicate the percent change elasticities of all income components to GNP growth, while panels A-2 through D-2 present the level change elasticities. Part A reports the results for the components of total 
income, Part B shows the results for the components of head's labor income, Part $\mathrm{C}$ shows the elasticities for components of wive's labor income, and Part D shows elasticities for components of transfers.

Part $A$ indicates how the aggregate components of income vary with GNP and reveals some striking patterns. First, total income among low income groups shows far greater percent increases than among high income groups. These results confirm that increases in GNP growth proportionately narrow the income distribution. However, the large percent changes in panel A-1 must be offset by looking at the level elasticities in panel A-2. Perhaps not surprisingly, absolute dollar changes are much larger among upper income groups. A $1 \%$ increase in GNP, leading to a $1.6 \%$ increase in income for the average poor household, means an extra $\$ 109$ to spend over the year. The top quintile household, whose income increases only $.85 \%$, gets an additional $\$ 433$ to spend.

Second, there are some groups whose income is quite unresponsive to GNP changes. In particular, female-headed households and the elderly have very low elasticities and gain little from economic growth. On the other hand, black male households and the young have very high elasticities. This meshes with the results cited above from research using more aggregate data sources.

Third, the driving force behind these elasticity patterns in total income is the elasticity of head's labor income. Percent changes are consistently larger for head's labor income than for total income. The only exception is among black female-headed households. Clearly, the smaller share of total income due to labor earnings among low income 


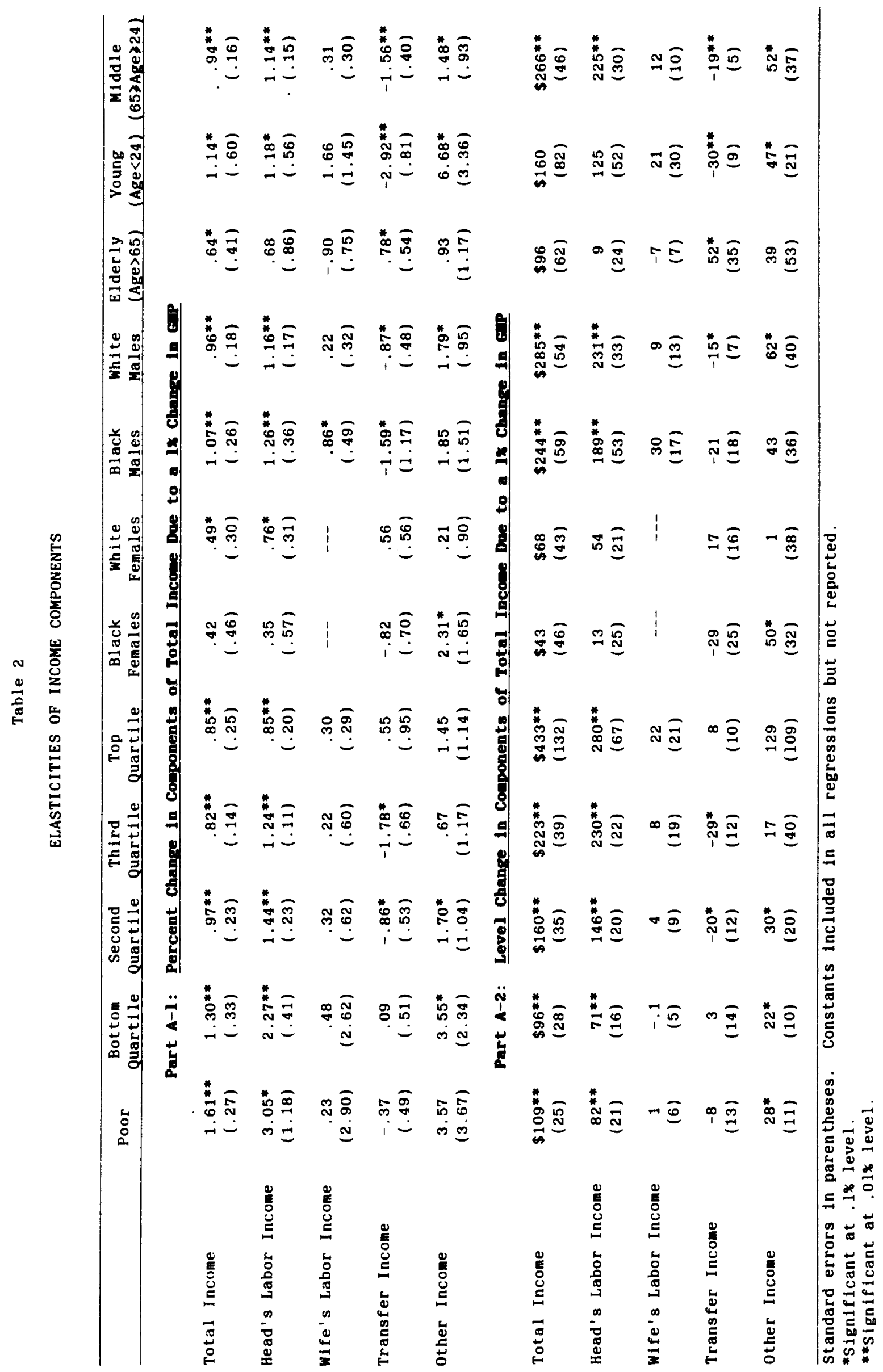




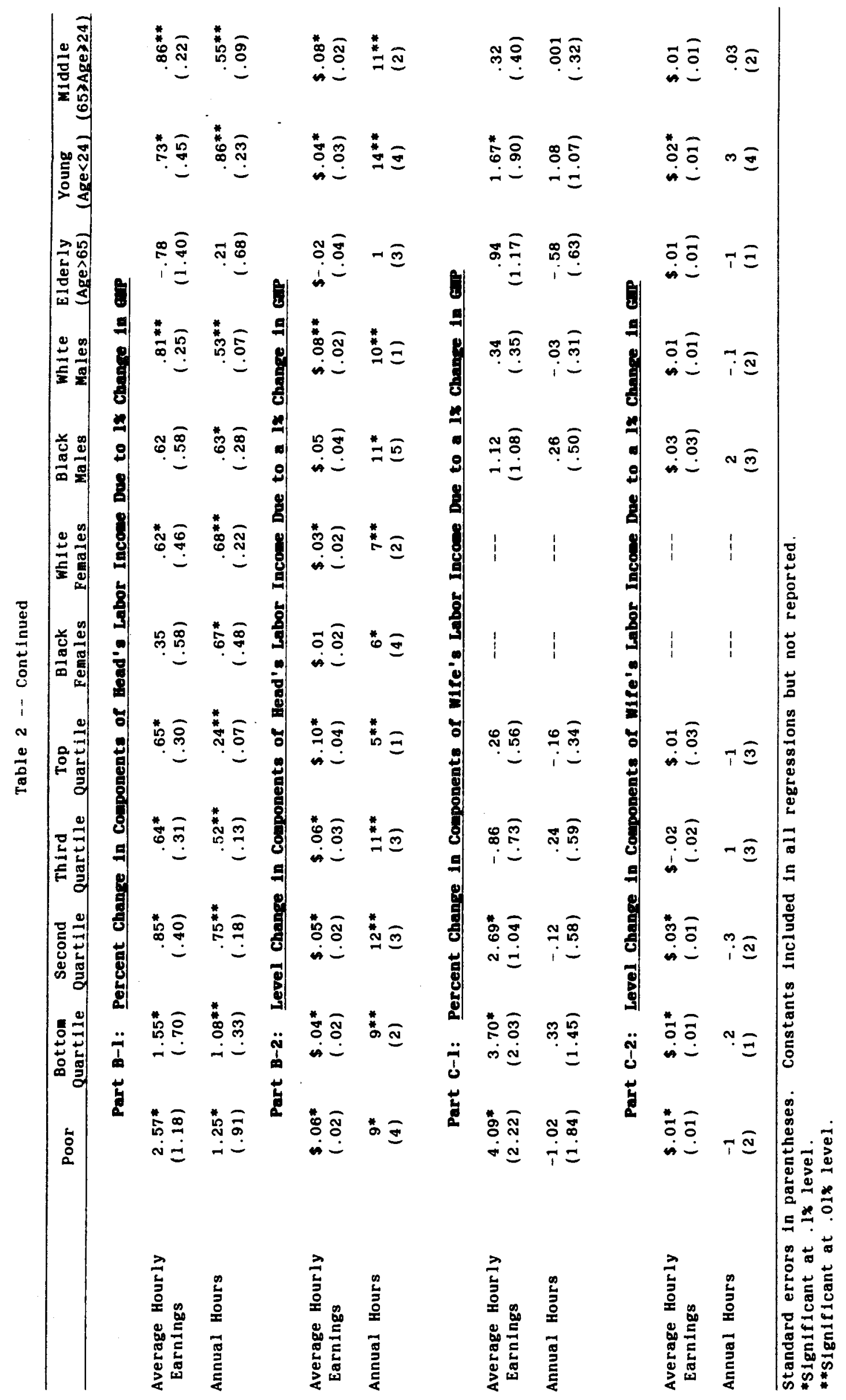




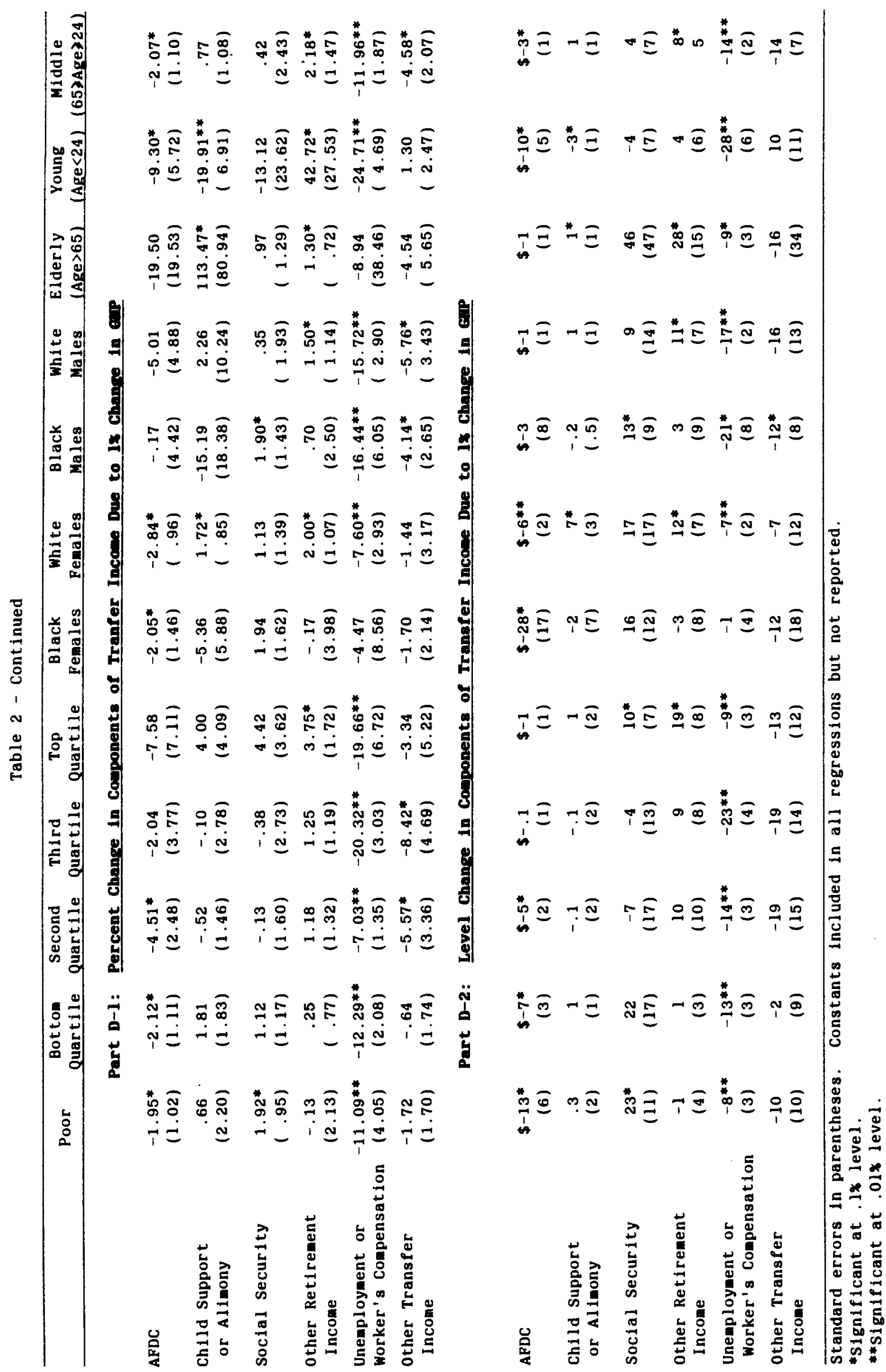


households (seen in Table 1) is offset by the very high relative elasticities on head's earnings, leading to a net narrowing effect in the income distribution as the economy grows.

$$
\text { Fourth, wife's labor income seems quite unresponsive to }
$$

macroeconomic change. Almost all groups show small procyclical, but insignificant, effects. Only the wives of black men and young men have labor market income that appears to increase proportionately with the economy. The wives of elderly men actually show a relatively large countercyclical effect.

Finally, transfer income shows mixed effects. Among the poorest groups transfers appear relatively unresponsive to GNP growth. Among more middle income groups, including male-headed households and young and middle-aged households, transfer income is strongly countercyclical.

Part B looks at the cyclicality of the components of head's labor income. Notice that the large percent changes in head's labor income among low income groups is due to higher elasticities of both hourly earnings and hours of work (although the changes in hours are estimated with greater precision.) ${ }^{21}$ Among the poor a $1 \%$ increase in GNP increases wages $2.57 \%$, or 6 cents an hour, and increases annual hours of work by $1.25 \%$ or 9 hours. Both of these effects decrease as income rises. Female-headed households -- black and white -- have the lowest elasticity of earnings.

These results are somewhat in contrast to theories of fixed wage/variable employment contracts which are often used to describe the labor market, and with macroeconomic studies indicating that aggregate real wages are largely unaffected by cyclical change. ${ }^{2}$ However, the 
finding that both wages and hours move over the cycle is consistent with recent research by Bils (1984), Coleman (1984) and Raisain (1983). ${ }^{23}$ One particular reason for significant wage cyclicality in this research is that I use a measure of wages which includes all labor market income (including overtime and second jobs) and imbeds movement in and out of the labor market. ${ }^{24}$

Part $C$ shows the components of wife's labor income and the patterns here are very different from head's earnings. Some wives appear to gain income over the cycle through large procyclical wage effects. Average hourly earnings of wives show strong percent increases among wives of low income and young heads, though these effects drop off rapidly at higher income levels. However, this translates into relatively small changes in wages, ${ }^{25}$ so that the level change in wages is approximately the same for women across all income categories. This further underscores the finding that women seem to be in jobs which are unresponsive to cyclical effects, protecting them against downturns, but also preventing them from gaining during upturns.

Cyclical effects on wives' annual hours are generally small. Past research has attempted to determine whether discouraged or added worker effects dominate labor supply behavior among married women. ${ }^{26}$ In Table 2 , these two effects appear to cancel each other out, with two exceptions. Wives in poor households appear to be added workers (a $1 \%$ increase in GNP leads to a $1.02 \%$ decrease in hours worked.) Wives of young heads seem to have an opposite response, increasing participation as the economy expands. However, none of these effects are welldetermined. 
Finally, Part D shows cyclical elasticities for the components of transfer income. Receipt of transfers is mildly countercyclical for low income groups and strongly countercyclical for richer groups. AFDC is negatively correlated with the cycle, while child support and alimony, along with other retirement income and social security, are procyclical. (This is partly due to legislative changes, which coincided with business cycle effects.) Unemployment compensation is strongly negatively correlated with GNP growth, particularly among young and white male households. For the elderly, who rely heavily on social security income, there is little correlation between this income source and the business cycle, although other retirement income is strongly procyclical for them. Black female-headed households seem to experience more counter-cyclicality in transfers than white female-headed households, although both rely heavily on a very similar mix of transfers. The young, black male-headed households, and the upper quartiles appear to face the greatest cyclicality in their transfer components. In absolute levels, the largest changes occur in unemployment and worker's compensation and in social security for most groups.

The regression results reported in Table 2 are quite simple in their form, containing just a constant and the percent change in GNP. A few more complex specifications were tried. A test of the symmetry of cyclical effects was run, separating the elasticity effects in the years in which GNP increased from the years in which it decreased. For no variable or population group did this produce a significantly different result from those reported here. Similarly, decomposing GNP into a 
trend and a cyclical component and entering each variable separately in these regressions produced little new information.

More informative was the addition of a nonlinear term, the square of the percent change in GNP. This was insignificant for all except female workers. For female household heads and for the wives of elderly and poor households, the nonlinear term had a significant negative effect on labor market income, primarily via significant negative effects on hours of work. This appears to indicate that these women, while gaining from the initial stages of a cyclical upturn, do not continue those gains at higher growth levels. Their ability to profit from continued economic growth falls off rapidly. These results are consistent with a theory that female heads and wives often have significant non-market claims on their time (such as children) that prevent them from making large hours increases when employment opportunities expand.

The estimates in Table 2 combine the effects of cyclical changes in labor market participation with cyclical changes in levels of work among already-working participants. Elasticities on labor market participation can be calculated separately. ${ }^{27}$ Changes over the cycle in the percent of households with working heads or wives are generally small and not highly significant. Approximately $1 / 2$ of 1 percent of the poor households and black female-headed households gain a working head when the economy grows $1 \%$. The effects for other groups are smaller. Among wives, there is a tendency for wives of low income groups to be added workers while wives of high income groups are discouraged workers (a finding consistent with other research cited above), but the effects 
are small and largely insignificant. These results indicate that the elasticity estimates for hours of work presented in Table 2 are largely the result of changes in the levels of hours and wages among workers, and not movement in and out of the labor force.

\section{VARIANCE ELASTICITIES}

The results in Table 2 indicate that the distribution of income between these 12 populations narrows over the cycle. This section investigates whether there are distributional changes within each population group, by looking at the change in the coefficient of variation of these income components as GNP changes. As noted above, there are reasons to believe that variance in some groups will increase with growth (a bifurcation among groups), and other arguments that indicate variances will decrease (the bottom catches up.) I use the coefficient of variation $\left(\operatorname{CVar}(X)_{j t}\right.$ for each income component $\left.X\right)$ to measure this effect since it is invariant to changes in the mean. ${ }^{28}$

Elasticities are calculated by regressing percent change in the coefficient of variation of each income component against percent change in GNP (and a constant.) The percent change in the coefficient of variation is calculated within each two year sample as,

$$
\operatorname{CVarCh}(X)_{j t}=\left[\operatorname{CVar}(X)_{j t+1}-\operatorname{CVar}(X)_{j t}\right] / \operatorname{CVar}(X)_{j t} .
$$

The percent change in the coefficient of variation of $X$ as GNP changes is determined in the regression equation

$$
\operatorname{CVarCh}(X)_{j t}=\gamma_{1}+\gamma_{2} \operatorname{PctGNP}_{t}+v_{j t},
$$

where PctGNP is defined above and $v$ is a random error term. Table 3 presents estimates of $\gamma_{2}$, showing the percent change in coefficient of variation resulting from a $1 \%$ change in GNP for each income component. 
The dominant conclusion from Part A of Table 3 is that short term cyclical growth not only narrows the income distribution between these population groups, but also narrows the income dispersion within these groups. Among almost all groups a significant decrease in the coefficient of variation of total income occurs as the economy grows. Black females alone show a small and insignificant change. (White females also show a relatively small change, although it is significant.) The poor show a larger, but poorly estimated effect.

The channel by which this narrowing occurs is also clear. The dispersion in labor market income of the head narrows significantly with the cycle for all groups except elderly and black female heads. Wive's labor market income shows few effects -- only among wives in upper income groups and among wives of white males and middle-aged is there significant narrowing. (These results are consistent with the results above which indicated that wives in low-income households and female heads benefit less from the cycle. The worst off among these groups seem unable to take advantage of economic growth to "catch up" and narrow the income distribution within the group.)

If we look at Parts $B$ and $C$ in Table 3 it is further clear that the narrowing in the coefficient of variation that occurs in labor market income seems to be occuring almost exclusively through changes in the distribution of annual hours. While the relative narrowing between groups occured because of greater cyclicality in both wages and hours among low-income groups, the narrowing dispersion of income within groups appears predominantly due to unemployed or underemployed heads working more hours. 


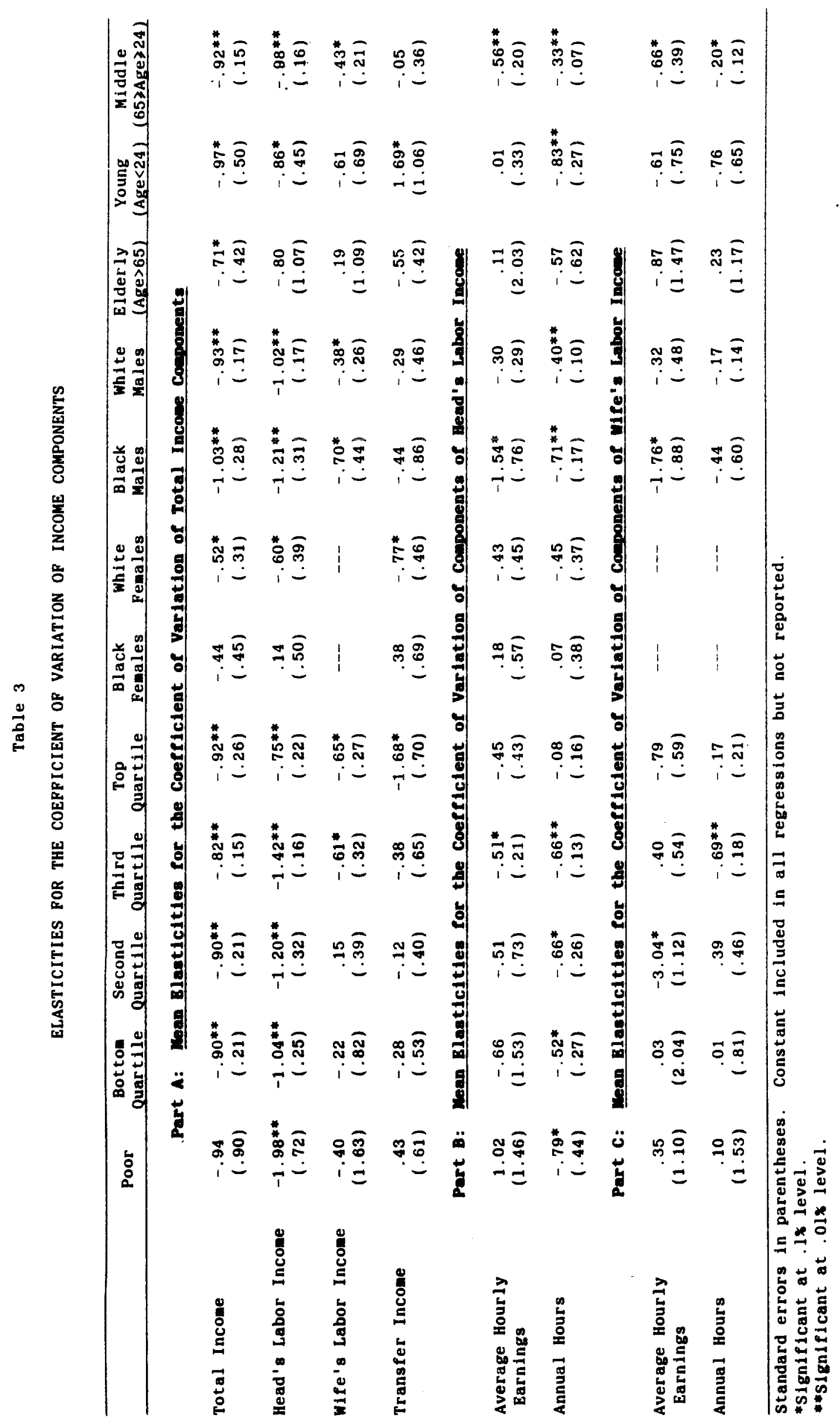


Elasticities of the coefficient of variation among components of transfer income are not reported here, largely because virtually no significant effects appear and few patterns are visible.

Thus among most groups I find evidence of a narrowing distribution in their labor market income as the economy grows, occuring due to narrowing in the distribution on annual hours. The groups for whom this effect is weakest are female heads and elderly households. Distributional patterns both between and within population groups change with macroeconomic cycles.

\section{CONCLUDING COMMENTS}

This study has decomposed total income among population groups into its various components and then studied the manner in which these components change with economic growth. The major conclusions were presented in the first section of this paper. In general, I find significant differences in elasticities both between different income components and between different population groups for the same components. The narrowing income distribution in times of high growth occurs primarily because of large elasticities on head's labor market income among the poor: Both wages and hours show evidence of cyclicality. The labor market earnings of women -- both wives and household heads -- are far less responsive to growth. Cyclicality in transfer income varies enormously between population groups and by type of transfer.

While this research uncovers a number of interesting patterns, it also raises a host of additional questions. Further exploration is needed of the causality behind many of the effects seen here. In 
particular, it would be interesting to focus more on the consistent nonresponsiveness of women's labor market income (both female head's and wife's) to the cycle. Also a closer investigation needs to be done of the comparative wage and hours cyclicality found here. In addition, further analysis of some of the cyclical effects among the components of transfer income would be of interest.

Finally, this study says nothing about the effects of changes in long-term secular growth rates within the macroeconomy. Over the time period of this study, no secular growth is apparent. However, the response of different groups in the population to short-term economic growth may be expected to have some correlation with their response to long-term growth. If so, it is clear that higher long-term growth rates for the U.S. economy would narrow the income distribution and help a significant number of currently low-income households. (An effect often referred to as "trickling down.") However, it is also true that these benefits would not be equally spread among the low income population. Especially among female household heads -- a group that has received a great deal of attention due to their high poverty rates -- economic growth alone is far from a panacea or solution. 


\section{FOOTNOTES}

1. See Beach (1977), Thornton, et. al. (1978) or Hirsch (1980). Blank and $\mathrm{B} 1$ inder (1986) review this literature.

2. One exception is the early work by Creamer (1958).

3. For instance, Mincer (1962), Raisain (1979, 1983), or Lundberg (1985).

4. See Gramlich and Laren (1984) or Rayack (1985).

5. Rayack looks at a very limited population, investigating only twoparent households which are stably married and where the husband is in the labor market for each of the 13 years in the study, excluding many low-income households. Gramlich and Laren look at three household groupings: female-headed, black and white maleheaded. They exclude households which are together less than 5 years, or whose prime earner is out of the labor market much of the time. Their focus is on cyclicality in total income and employment.

6. Of course, I could further decompose Hours into Hours per Week and Weeks per Year. This is not done because the data available on these two variables in my data set (the PSID) is more suspect than the data on AHE and Hours. For many individuals, it is missing.

7. The largest welfare program in the "other" category is Supplementary Security Income (SSI). SSI is created at the Federal level in the middle of my data. Prior to its emergence many households received transfers from a variety of state-run programs, which cannot be separately identified. It was easiest to leave all of this in the "other transfers" category. Compared to Social Security and AFDC, SSI is a far less significant program.

8. While it would be interesting to separate out these other labor market earnings, there is a limit to the number of variables easily examined in one paper. Earnings of the head and spouse represent over $96 \%$ of average household labor market income.

9. For a full explanation of the difference, see The User Guide to the PSID (1984). The $125 \%$ number is selected because my data set (the PSID, discussed more fully below) consistently finds more household income than the Census. This is the accepted way of defining a poverty standard for this data that identifies approximately the same population as the standard Census definition of poverty. For instance, this definition is used by Bane and Ellwood (1986) in their PSID-based study of the dynamics of poverty.

10. Like all self-reported surveys, the PSID is subject to underreporting of both transfer income and asset income. Therefore, compared to the National Income Accounts, it shows less income from these two categories. (There are also definitional problems in comparing NIA data to PSID data.) However, the PSID 
does appear more accurate (at least in its information on transfers) than the Current Population Survey. The trends in income components from the PSID match closely with those reported els ewhere.

11. Realize that this data set is somewhat different from many others. Typically, one either has extensive cross-sectional data for one year only (such as a CPS survey) or one has aggregate mean data from different random samples taken each year (such as annual wages or unemployment rates.) In contrast, my data set allows one to estimate changes between years among the same households. But successive changes come from different cross sections, weighted to appear as identical random samples of the population.

12. This study makes no attempt to separately identify permanent and transitory income effects. For instance, households could potentially be grouped by income according to their permanent, rather their current, income. This is not done for two reasons. First, I am interested in knowing the effect of cyclical changes on the apparent income distribution. Among those whose income grows when the macro economy improves there will be some who are experiencing long-term income growth and others who are simply recovering from a short-term income fluctuation. It is left to future research to separately estimate the extent of these two effects. Second and more practically, there are serious empirical problems in satisfactorially estimating permanent income levels for households that change headship and composition frequently. The groups in which I am most interested -- low income or femaleheaded -- are precisely those for whom this problem is most acute.

13. In population group $j$ at time $t$ the mean level of any income component, $X$, among those who receive it is

$$
\bar{x}_{j t}=\sum_{i=1}^{n_{x j t}} x_{i j t} / n_{x j t} \text {, }
$$

where $n_{x j t}$ is the number of households in group $j$ in year $t$ who

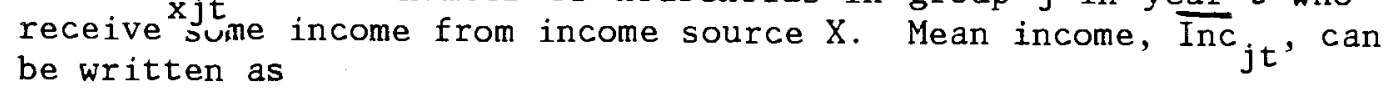

$$
\begin{aligned}
\overline{\operatorname{Inc}}_{j t}= & \left(\% \text { LIncH }_{j t}\right) * \overline{\operatorname{LIncH}}_{j t}+\left(\% \text { LIncW }_{j t}\right) * \overline{\operatorname{LIncW}}_{j t}+ \\
& +\left(\% \operatorname{Tr}_{j t}\right) * \overline{\operatorname{Transfers}}_{j t}+\left(\% 0 \mathrm{th}_{j t}\right) * \overline{0 \text { thInc }}_{j t},
\end{aligned}
$$

where $\left(\% \mathrm{X}_{j t}\right)$ is the percent of group $j$ in year $t$ for whom income component ${ }^{j}$ is non-zero. The mean share of total income due to component $X$ for any year $t$ for any group $j$ is

$$
\operatorname{SHARE}(X)_{j t}=\sum_{i=1}^{n_{j t}}\left(X_{i j t} / \operatorname{Inc}_{i j t}\right) / n_{j t} \text {, }
$$

where $n_{i t}$ is the number of households in group $j$ in year $t$. Mean levels of income components and shares across all 12 years for each population are estimated by averaging the yearly means for each variable across the 12 years: 


$$
\overline{\bar{X}}_{j}=\sum_{t=1}^{12} \bar{x}_{j t} / 12
$$

14. One way of interpreting these numbers is that the labor supply functions governing behavior of workers at different income levels are different. Low income household heads supply more hours of work at their mean wage rates than do higher income households.

15. Underreporting of transfer income may affect these numbers.

16. Median family income (in 1981 dollars) in 1969 was $\$ 23,482$. In 1981 it was almost unchanged at $\$ 23,282$. Per capita disposable income and per capita consumption expenditures increase over this period. The discrepancy appears primarily due first, to the splintering of households, with single person and single parent households growing faster than the total population; and second, to the use of the CPI to deflate median income. (The CPI has increased faster than the deflators which are used in the National Income Accounts.)

17. For instance, many researchers regularly attempt to enter state or even county unemployment rates into micro-data labor force participation estimates. Although one might believe that unemployment rates should affect household labor force decisions, the coefficients on these aggregate unemployment rates rarely appear different from zero.

18. Of course, GNP is not the only possible measure of cyclicality. In particular, some studies have used changes in unemployment rates. I choose to use GNP for two reasons. First, most of the "trickle down" theories explicitly refer to macroeconomic growth as the primary channel by which the income distribution is affected. GNP growth is the most frequently used measure of this. Second, the unemployment rate over these 12 years experienced a significant amount of change due to shifting demographic patterns, producing a steady increase in the average underlying rate of unemployment between 1969 and 1981. This means that unemployment changes imbed both demographic and cyclical effects, making them a less attractive measure of cyclical change.

19. Rather than the percent change of the means, I could calculate the mean of the percent changes. However, this would create difficulties as nonrecipients in year $t$ would have zeros in the denominator.

20. Rather than use mean income components for each population group as my dependent variables, I could regress individual household observations against aggregate GNP changes. Rather than 12 observations, I would then have many thousands. However, this alternative is costly to implement and both estimating techniques should produce identical coefficients since OLS fits a line through the means. The standard errors will vary, and it is impossible to say a priori which set of standard errors will be lower. Under reasonable assumptions one could expect that the standard errors on my estimates will be larger, implying that my 
significance levels may be understated relative to a fully efficient estimator.

21. The extent to which the change in hours is due to an increase in labor force participation is discussed below.

22. For instance, Altonji and Ashenfelter (1980) find that wages appear to follow a random walk. Geary and Kennan (1982) reach similar conclusions.

23. Coleman indicates that wage cyclicality is a phenomenon of the 1970s; studies using earlier data found few cyclical effects.

24. The wage measure used here is the ratio of all labor market income over annual hours of work. Explicit wage rates are not available for the entire sample during the 12 years which I am analyzing.

25. Recall that the level elasticity is the expected level change due to a $1 \%$ increase in GNP calculated over the entire population. Since many wives do not work, these expected level changes are quite small. This also means the base of the percent change calculation is small, so small absolute changes in levels can produce large percent changes.

26. The classical work on the cyclicality of wife's income is Mincer (1962), who finds almost no cyclical effects. On the other hand, quite a few cross-sectional studies have found strong negative relationships between wife's participation and husband's earnings. Most recently, see Ransom (1982) and Lundberg (1985). My results, showing large added worker effects only among poor wives, is consistent with this other research.

27. See the working paper, Blank (1985), for a more complete presentation of these results.

28. As noted above, there are consistent changes in the mean of some of these income components for certain populations over a two-year period. (For instance, among the young, income grows.) In general, the coefficient of variation measures the dispersion of the variable in each year, adjusting for these mean changes. The coefficient of variation of income component $X$ for population $j$ in year $t$ is

(e) $\quad C \operatorname{Var}(x)_{j t}=\left[\sum_{i=1}^{n_{x j t}}\left(x_{i j t}-\bar{x}_{j t}\right)^{2} / n_{x j t}\right]^{1 / 2} /\left[\sum_{i=1}^{n_{x j t}} x_{i j t} / n_{x j t !}\right]$, where $n_{x j t}$ households in group $j$ in this year receive income
compone $e_{i L}$. 


\section{REFERENCES}

Joseph Altonji and Orley Ashenfelter, "Wage Movements and the Labor Market Equilibrium Hypothesis," ECONOMICA. August 1980. pp217-245.

Mary Jo Bane and David T. Ellwood, "Slipping Into and Out of Poverty: The Dynamics of Spells," JOURNAL OF HUMAN RESOURCES. Winter 1986. pp1-23.

Charles M. Beach, "Cyclical Sensitivity of Aggregate Income Inequality," REVIEW OF ECONOMICS AND STATISTICS. February 1977. pp56-66.

Mark Bils, "Real Wages over the Business Cycle: Evidence from Panel Data," JOURNAL OF POLITICAL ECONOMY. August 1985. pp666-689.

Rebecca M. Blank, "Disaggregating the Effect of Economic Growth on the Distribution of Income," Institute for Research on Poverty Working Paper 非780-85, 1985 .

Rebecca M. Blank and Alan S. Blinder, "Macroeconomics, Income Distribution and Poverty," in FIGHTING POVERTY: WHAT WORKS AND WHAT DOES NOT, Sheldon Danziger and Danial Weinberg, eds. Cambridge, MA: Harvard University Press. 1986. pp180-208.

Thomas S. Coleman, "Essays on Aggregate Labor Market Business Cycle Fluctuations," Ph.D. thesis. University of Chicago. December 1984 .

Daniel Creamer, PERSONAL INCOME DURING BUSINESS CYCLES. Princeton: Princeton University Press. 1956.

Patrick T. Geary and John Kennan, "The Employment-Real Wage Relationship: An International Study," JOURNAL OF POLITICAL ECONOMY. August 1982. pp854-867.

Edward M. Gramlich and Deborah S. Laren, "How Widespread Are Income Losses in a Recession?" In THE SOCIAL CONTRACT REVISITED, D. Lee Bawden, editor. Washington D.C.: The Urban Institute. 1984. pp157-180.

Barry T. Hirsch, "Poverty and Economic Growth: Has Trickle-Down Petered Out?" ECONOMIC INQUIRY. January 1980. pp 151-158.

Shelly Lundberg, "The Added Worker Effect," JOURNAL OF LABOR ECONOMICS. January 1985. ppl1-37.

Jacob Mincer, "Labor Force Participation of Married Women: A Study of Labor Supply," In ASPECTS OF LABOR ECONOMICS. Princeton, N.J.: Princeton S University Press. 1962. pp63-105.

John Raisain, "Cyclic Patterns in Weeks and Wages," ECONOMIC INQUIRY. October 1979. pp475-495. 
"Contracts, Job Experience and Cyclical Labor Market Adjustments," JOURNAL OF LABOR ECONOMICS. April 1983. pp152-170.

W. L. Rayack, "The Distributional Impact of Recession: An Analysis of Earnings-Sensitivity by Family Income Class," Working paper. 1985.

Michael R. Ransom, "Estimating Family Labor Supply Models Under Quantity Constraints," Industrial Relations Section Working Paper No. 150, Princeton University. July 1982.

James R. Thornton, Richard J. Agnello and Charles R. Link, "Poverty and Economic growth: Trickle Down Peters Out," ECONOMIC INQUIRY. June 1978. pp 385-394. 